\title{
Hybrid Algorithm of Fixed Point for Weak Relatively Nonexpansive Multivalued Mappings and Applications
}

\author{
Jingling Zhang, Yongfu Su, and Qingqing Cheng \\ Department of Mathematics, Tianjin Polytechnic University, Tianjin 300387, China \\ Correspondence should be addressed to Yongfu Su, suyongfu@tjpu.edu.cn
}

Received 22 May 2012; Accepted 5 July 2012

Academic Editor: Yonghong Yao

Copyright (C) 2012 Jingling Zhang et al. This is an open access article distributed under the Creative Commons Attribution License, which permits unrestricted use, distribution, and reproduction in any medium, provided the original work is properly cited.

The purpose of this paper is to present the notion of weak relatively nonexpansive multivalued mapping and to prove the strong convergence theorems of fixed point for weak relatively nonexpansive multivalued mappings in Banach spaces. The weak relatively nonexpansive multivalued mappings are more generalized than relatively nonexpansive multivalued mappings. In this paper, an example will be given which is a weak relatively nonexpansive multivalued mapping but not a relatively nonexpansive multivalued mapping. In order to get the strong convergence theorems for weak relatively nonexpansive multivalued mappings, a new monotone hybrid iteration algorithm with generalized (metric) projection is presented and is used to approximate the fixed point of weak relatively nonexpansive multivalued mappings. In this paper, the notion of multivalued resolvent of maximal monotone operator has been also presented which is a weak relatively nonexpansive multivalued mapping and can be used to find the zero point of maximal monotone operator.

\section{Introduction and Preliminaries}

Iterative methods for approximating fixed points of multivalued mappings in Banach spaces have been studied by some authors, see for instance [1-4]. Let $C$ be a nonempty closed convex subset of a smooth Banach space $E$ and $T: C \rightarrow C$ a multivalued mapping such that $T x$ is nonempty for all $x \in C$. In [4], Homaeipour and Razani have defined the relatively nonexpansive multivalued mapping and have proved some convergence theorems.

Theorem SA 1 (see [4]). Let E be a uniformly convex and uniformly smooth Banach space, and C a nonempty closed convex subset of $E$. Suppose $T: C \rightarrow C$ is a relatively nonexpansive multivalued 
mapping. Let $\left\{\alpha_{n}\right\}$ be a sequence of real numbers such that $0 \leq \alpha_{n} \leq 1$ and $\lim _{\inf } \lim _{n \rightarrow \infty} \alpha_{n}\left(1-\alpha_{n}\right)>0$. For a given $x_{1} \in C$, let $\left\{x_{n}\right\}$ be the iterative sequence defined by

$$
x_{n+1}=\Pi_{C} J^{-1}\left(\alpha_{n} J x_{n}+\left(1-\alpha_{n}\right) J z_{n}\right), \quad z_{n} \in T x_{n} .
$$

If $J$ is weakly sequentially continuous, then $\left\{x_{n}\right\}$ converges weakly to a fixed point of $T$.

Theorem SA 2 (see [4]). Let E be a uniformly convex and uniformly smooth Banach space, and C a nonempty closed convex subset of $E$. Suppose $T: C \rightarrow C$ is a relatively nonexpansive multivalued mapping. Let $\left\{\alpha_{n}\right\}$ be a sequence of real numbers such that $0 \leq \alpha_{n} \leq 1$ and $\lim _{\inf }{ }_{n \rightarrow \infty} \alpha_{n}\left(1-\alpha_{n}\right)>0$. For a given $x_{1} \in C$, let $\left\{x_{n}\right\}$ be the iterative sequence defined by

$$
x_{n+1}=\Pi_{C} J^{-1}\left(\alpha_{n} J x_{n}+\left(1-\alpha_{n}\right) J z_{n}\right), \quad z_{n} \in T x_{n} .
$$

If the interior of $F(T)$ is nonempty, then $\left\{x_{n}\right\}$ converges strongly to a fixed point of $T$.

Let $E$ be a Banach space with dual $E^{*}$. We denote by $J$ the normalized duality mapping from $E$ to $2^{E^{*}}$ defined by

$$
J x=\left\{f \in E^{*}:\langle x, f\rangle=\|x\|^{2}=\|f\|^{2}\right\},
$$

where $\langle\cdot, \cdot\rangle$ denotes the generalized duality pairing. It is well known that if $E^{*}$ is uniformly convex, then $J$ is uniformly continuous on bounded subsets of $E$.

As we all know that if $C$ is a nonempty closed convex subset of a Hilbert space $H$ and $P_{C}: H \rightarrow C$ is the metric projection of $H$ onto $C$, then $P_{C}$ is nonexpansive. This fact actually characterizes Hilbert spaces, and consequently it is not available in more general Banach spaces. In this connection, Alber [5] recently introduced a generalized projection operator $\Pi_{C}$ in a Banach space $E$ which is an analogue of the metric projection in Hilbert spaces.

Next, we assume that $E$ is a smooth Banach space. Consider the functional defined as $[5,6]$ by

$$
\phi(x, y)=\|x\|^{2}-2\langle x, J y\rangle+\|y\|^{2}, \quad \text { for } x, y \in E .
$$

Observe that, in a Hilbert space $H,(1.4)$ reduces to $\phi(x, y)=\|x-y\|^{2}, x, y \in H$.

The generalized projection $\Pi_{C}: E \rightarrow C$ is a map that assigns to an arbitrary point $x \in E$ the minimum point of the functional $\phi(x, y)$, that is, $\Pi_{C} x=\bar{x}$, where $\bar{x}$ is the solution to the following minimization problem:

$$
\phi(\bar{x}, x)=\min _{y \in C} \phi(y, x),
$$

existence and uniqueness of the operator $\Pi_{C}$ follow from the properties of the functional $\phi(x, y)$ and strict monotonicity of the mapping $J$ (see, eg., [5-7]). In Hilbert space, $\Pi_{C}=P_{C}$. It is obvious from the definition of function $\phi$ that

$$
(\|y\|-\|x\|)^{2} \leq \phi(y, x) \leq(\|y\|+\|x\|)^{2}, \quad \forall x, y \in E .
$$


Remark 1.1. If $E$ is a reflexive strictly convex and smooth Banach space, then for $x, y \in E$, $\phi(x, y)=0$ if and only if $x=y$. It is sufficient to show that if $\phi(x, y)=0$ then $x=y$. From (1.6), we have $\|x\|=\|y\|$. This implies $\langle x, J y\rangle=\|x\|^{2}=\|J y\|^{2}$. From the definitions of $j$, we have $J x=J y$, that is, $x=y$, see $[8,9]$ for more details.

Let $C$ be a nonempty closed convex subset of a smooth Banach space $E$ and $T: C \rightarrow C$ a multivalued mapping such that $T x$ is nonempty for all $x \in C$. A point $p$ is called a fixed point of $T$, if $p \in T p$. The set of fixed points of $T$ is represented by $F(T)$. A point $p \in C$ is called an asymptotic fixed point of $T$, if there exists a sequence $\left\{x_{n}\right\}$ in $C$ which converges weakly to $p$ and $\lim _{n \rightarrow \infty} d\left(x_{n}, T x_{n}\right)=0$, where $d\left(x_{n}, T x_{n}\right)=\inf _{u \in T x_{n}}\left\|x_{n}-u\right\|$. The set of asymptotic fixed points of $T$ is represented by $\widehat{F}(T)$. Moreover, a multivalued mapping $T: C \rightarrow C$ is called relatively nonexpansive multivalued mapping, if the following conditions are satisfied:

(1) $F(T) \neq \emptyset$,

(2) $\phi(p, z) \leq \phi(p, x)$, for all $p \in F(T)$, for all $x \in C$, for all $z \in T x$,

(3) $\widehat{F}(T)=F(T)$.

In [4], authors also give an example which is a relatively nonexpansive multivalued mapping but not a nonexpansive multivalued mapping.

The purpose of this paper is to present the notion of weak relatively nonexpansive multivalued mapping and to prove the strong convergence theorems for the weak relatively nonexpansive multivalued mappings in Banach spaces. The weak relatively nonexpansive multivalued mappings are more generalized than relatively nonexpansive multivalued mappings. In this paper, an example will be given which is a weak relatively nonexpansive multivalued mapping but not a relatively nonexpansive multivalued mapping. In order to get the strong convergence theorems for weak relatively nonexpansive multivalued mappings, a new monotone hybrid iteration algorithm with generalized (metric) projection is presented and is used to approximate the fixed point of weak relatively nonexpansive multivalued mappings. We first give the definition of weak relatively nonexpansive multivalued mapping as follows.

Let $C$ be a nonempty closed convex subset of a smooth Banach space $E$ and $T: C \rightarrow C$ a multivalued mapping such that $T x$ is nonempty for all $x \in C$. A point $p \in C$ is called an strong asymptotic fixed point of $T$, if there exists a sequence $\left\{x_{n}\right\}$ in $C$ which converges strongly to $p$ and $\lim _{n \rightarrow \infty} d\left(x_{n}, T x_{n}\right)=0$, where $d\left(x_{n}, T x_{n}\right)=\inf _{u \in T x_{n}}\left\|x_{n}-u\right\|$. The set of the strong asymptotic fixed points of $T$ is represented by $\widetilde{F}(T)$. Moreover, a multivalued mapping $T: C \rightarrow C$ is called weak relatively nonexpansive multivalued mapping, if the following conditions are satisfied:

(I) $F(T) \neq \emptyset$,

(II) $\phi(p, z) \leq \phi(p, x)$, for all $p \in F(T)$, for all $x \in C$, for all $z \in T x$,

(III) $\tilde{F}(T)=F(T)$.

We need the following Lemmas for the proof of our main results.

Lemma 1.2 (see Kamimura and Takahashi [7]). Let E be a uniformly convex and smooth Banach space and let $\left\{x_{n}\right\},\left\{y_{n}\right\}$ be two sequences of $E$. If $\phi\left(x_{n}, y_{n}\right) \rightarrow 0$ and either $\left\{x_{n}\right\}$ or $\left\{y_{n}\right\}$ is bounded, then $x_{n}-y_{n} \rightarrow 0$. 
Lemma 1.3 (see Alber [5]). Let $C$ be a nonempty closed convex subset of a smooth Banach space $E$ and $x \in E$. Then, $x_{0}=\Pi_{C} x$ if and only if

$$
\left\langle x_{0}-y_{1} J x-J x_{0}\right\rangle \geq 0, \quad \text { for } y \in C \text {. }
$$

Lemma 1.4 (see Alber [5]). Let E be a reflexive, strictly convex and smooth Banach space, let $C$ be a nonempty closed convex subset of $E$, and let $x \in E$. Then

$$
\phi\left(y, \Pi_{c} x\right)+\phi\left(\Pi_{c} x, x\right) \leq \phi(y, x), \quad \forall y \in C
$$

Lemma 1.5. Let $E$ be a uniformly convex and smooth Banach space, let $C$ be a closed convex subset of $E$, and let $T: C \rightarrow C$ be a weak relatively nonexpansive multivalued mapping. Then $F(T)$ is closed and convex.

Proof. First, we show $F(T)$ is closed. Let $\left\{x_{n}\right\}$ be a sequence in $F(T)$ such that $x_{n} \rightarrow q$. Since $T$ is weak relatively nonexpansive multivalued mapping, we have

$$
\phi\left(x_{n}, z\right) \leq \phi\left(x_{n}, q\right), \quad \forall z \in T q, n=1,2,3, \ldots
$$

Therefore

$$
\phi(q, z)=\lim _{n \rightarrow \infty} \phi\left(x_{n}, z\right) \leq \lim _{n \rightarrow \infty} \phi\left(x_{n}, q\right)=\phi(q, q)=0 .
$$

By Lemma 1.2, we have $q=z$, hence, $T q=\{q\}$, so $q \in F(T)$. Therefore $F(T)$ is closed. Next, we show $F(T)$ is convex. Let $x, y \in F(T)$, put $z=t x+(1-t) y$ for any $t \in(0,1)$. For $w \in T z$, we have

$$
\begin{aligned}
\phi(z, w) & =\|z\|^{2}-2\langle z, J w\rangle+\|w\|^{2} \\
& =\|z\|^{2}-2\langle t x+(1-t) y, J w\rangle+\|w\|^{2} \\
& =\|z\|^{2}-2 t\langle x, J w\rangle-2(1-t)\langle y, J w\rangle+\|w\|^{2} \\
& =\|z\|^{2}+t \phi(x, w)+(1-t) \phi(y, w)-t\|x\|^{2}-(1-t)\|y\|^{2} \\
& \leq\|z\|^{2}+t \phi(x, z)+(1-t) \phi(y, z)-t\|x\|^{2}-(1-t)\|y\|^{2} \\
& =\|z\|^{2}-2\langle t x+(1-t) y, J z\rangle+\|z\|^{2} \\
& =\|z\|^{2}-2\langle z, J z\rangle+\|z\|^{2} \\
& =\phi(z, z)=0 .
\end{aligned}
$$

By Lemma 1.2, we have $z=w$, so $z \in T z$, that is $z \in F(T)$. Therefore, $F(T)$ is convex. This completes the proof. 
Remark 1.6. Let $E$ be a strictly convex and smooth Banach space, and $C$ a nonempty closed convex subset of $E$. Suppose $T: C \rightarrow C$ is a weak relatively nonexpansive multivalued mapping. If $p \in F(T)$, then $T(p)=\{p\}$.

\section{An Example of Weak Relatively Nonexpansive Multivalued Mapping}

Next, we give an example which is a weak relatively nonexpansive multivalued mapping but not a relatively nonexpansive multivalued mapping.

Example 2.1. Let $E=l^{2}$ and

$$
\begin{gathered}
x_{0}=(1,0,0,0, \ldots) \\
x_{1}=(1,1,0,0, \ldots) \\
x_{2}=(1,0,1,0,0, \ldots) \\
x_{3}=(1,0,0,1,0,0, \ldots) \\
\ldots \\
x_{n}=(1,0,1,0,0, \ldots, 0,1,0,0,0, \ldots)
\end{gathered}
$$

It is obvious that $\left\{x_{n}\right\}_{n=1}^{\infty}$ converges weakly to $x_{0}$. On the other hand, we have $\left\|x_{n}-x_{m}\right\|=\sqrt{2}$ for any $n \neq m$. Define a mapping $T: E \rightarrow 2^{E}$ as follows:

$$
T(x)= \begin{cases}\left\{y=t x_{n}: \frac{n}{n+2} \leq t \leq \frac{n}{n+1}\right\}, & \text { if } x=x_{n}(\exists n \geq 1) \\ -x, & \text { if } x \neq x_{n}(\forall n \geq 1)\end{cases}
$$

It is also obvious that $F(T)=\{0\}$ and

$$
\|0-y\|=\|y\| \leq\|x\|=\|0-x\|, \quad \forall x \in E, y \in T x .
$$

Since $E=L^{2}$ is a Hilbert space, we have

$$
\phi(0, y)=\|0-y\|^{2}=\|y\|^{2} \leq\|x\|^{2}=\|0-x\|^{2}=\phi(0, x), \quad \forall x \in E, y \in T x .
$$

Next, we prove $\widehat{F}(T)=F(T)$. In fact, that for any strong convergent sequence $\left\{z_{n}\right\} \subset E$ such that $z_{n} \rightarrow z_{0}$ and $d\left(z_{n}, T z_{n}\right) \rightarrow 0$ as $n \rightarrow \infty$, then there exist sufficiently large nature number $N$ such that $z_{n} \neq x_{m}$, for any $n, m>N$. Then $T z_{n}=-z_{n}$ for $n>N$, it follows from

$$
\left\|z_{n}-T z_{n}\right\|=d\left(z_{n}, T z_{n}\right) \longrightarrow 0
$$


that $2 z_{n} \rightarrow 0$ and hence $z_{n} \rightarrow z_{0}=0$, this implies $z_{0} \in F(T)$, so that $\widehat{F}(T)=F(T)$. Then $T$ is a weak relatively multivalued nonexpansive mapping.

We second claim that $T$ is not relatively multivalued nonexpansive mapping. In fact, that $x_{n} \rightarrow x_{0}$ and

$$
d\left(x_{n}, T x_{n}\right) \leq\left(\frac{n}{n+1}-\frac{n}{n+2}\right) \longrightarrow 0
$$

as $n \rightarrow \infty$ hold, but $x_{0} \bar{\epsilon} F(T)$.

\section{Strong Convergence of Monotone Hybrid Algorithm}

Theorem 3.1. Let $E$ be a uniformly convex and uniformly smooth Banach space, let $C$ be a nonempty closed convex subset of $E$, and let $T: C \rightarrow C$ be a weak relatively multivalued nonexpansive mapping such that $F(T) \neq \emptyset$. Assume that $\left\{\alpha_{n}\right\}_{n=0}^{\infty},\left\{\beta_{n}\right\}_{n=0}^{\infty},\left\{\gamma_{n}\right\}_{n=0}^{\infty}$ are three sequences in $[0,1]$ such that $\alpha_{n}+\beta_{n}+\gamma_{n}=1, \lim _{n \rightarrow \infty} \alpha_{n}=0$ and $0<\gamma \leq \gamma_{n} \leq 1$ for some constant $\gamma \in(0,1)$. Define a sequence $\left\{x_{n}\right\}$ in $C$ by the following algorithm:

$$
\begin{gathered}
x_{0} \in C \quad \text { arbitrarily, } \\
y_{n}=J^{-1}\left(\alpha_{n} J x_{0}+\beta_{n} J x_{n}+\gamma_{n} J z_{n}\right), \quad z_{n} \in T x_{n} \\
C_{n}=\left\{z \in C_{n-1}: \phi\left(z, y_{n}\right) \leq\left(1-\alpha_{n}\right) \phi\left(z, x_{n}\right)+\alpha_{n} \phi\left(z, x_{0}\right)\right\}, \quad n \geq 1, \\
C_{0}=C, \\
x_{n+1}=\prod_{C_{n}} x_{0},
\end{gathered}
$$

then $\left\{x_{n}\right\}$ converges to $q=\Pi_{F(T)} x_{0}$.

Proof. We first show that $C_{n}$ is closed and convex for all $n \geq 0$. From the definitions of $C_{n}$, it is obvious that $C_{n}$ is closed for all $n \geq 0$. Next, we prove that $C_{n}$ is convex for all $n \geq 0$. Since

$$
\phi\left(z, y_{n}\right) \leq\left(1-\alpha_{n}\right) \phi\left(z, x_{n}\right)+\alpha_{n} \phi\left(z, x_{0}\right)
$$

is equivalent to

$$
2\left\langle z,\left(1-\alpha_{n}\right) J x_{n}+\alpha_{n} J x_{0}-J y_{n}\right\rangle \leq\left(1-\alpha_{n}\right)\left\|x_{n}\right\|^{2}+\alpha_{n}\left\|x_{0}\right\|^{2}
$$

It is easy to get that $C_{n}$ is convex for all $n \geq 0$. 
Next, we show that $F(T) \subset C_{n}$ for all $n \geq 0$. Indeed, for each $p \in F(T)$, we have

$$
\begin{aligned}
\phi\left(p, y_{n}\right)= & \phi\left(p, J^{-1}\left(\alpha_{n} J x_{0}+\beta_{n} J x_{n}+\gamma_{n} J z_{n}\right)\right) \\
= & \|p\|^{2}-2\left\langle p, \alpha_{n} J x_{0}+\beta_{n} J x_{n}+\gamma_{n} J z_{n}\right\rangle \\
& \left.+\| \alpha_{n} J x_{0}+\beta_{n} J x_{n}+\gamma_{n} J z_{n}\right) \|^{2} \\
\leq & \|p\|^{2}-2 \alpha_{n}\left\langle p, J x_{0}\right\rangle-2 \beta_{n}\left\langle p, J x_{n}\right\rangle-2 \gamma_{n}\left\langle p, J z_{n}\right\rangle \\
& +\alpha_{n}\left\|x_{0}\right\|^{2}+\beta_{n}\left\|x_{n}\right\|+\gamma_{n}\left\|z_{n}\right\|^{2} \\
\leq & \alpha_{n} \phi\left(p, x_{0}\right)+\beta_{n} \phi\left(p, x_{n}\right)+\gamma_{n} \phi\left(p, z_{n}\right) \\
\leq & \alpha_{n} \phi\left(p, x_{0}\right)+\beta_{n} \phi\left(p, x_{n}\right)+\gamma_{n} \phi\left(p, x_{n}\right) \\
\leq & \alpha_{n} \phi\left(p, x_{0}\right)+\left(1-\alpha_{n}\right) \phi\left(p, x_{n}\right) .
\end{aligned}
$$

So, $p \in C_{n}$, which implies that $F(T) \subset C_{n}$ for all $n \geq 0$.

Since $x_{n+1}=\Pi_{C_{n}} x_{0}$ and $C_{n} \subset C_{n-1}$, then we get

$$
\phi\left(x_{n}, x_{0}\right) \leq \phi\left(x_{n+1}, x_{0}\right), \quad \forall n \geq 0 .
$$

Therefore, $\left\{\phi\left(x_{n}, x_{0}\right)\right\}$ is nondecreasing. On the other hand, by Lemma 1.4 we have

$$
\phi\left(x_{n}, x_{0}\right)=\phi\left(\Pi_{C_{n-1}} x_{0}, x_{0}\right) \leq \phi\left(p, x_{0}\right)-\phi\left(p, x_{n}\right) \leq \phi\left(p, x_{0}\right),
$$

for all $p \in F(T) \subset C_{n-1}$ and for all $n \geq 1$. Therefore, $\phi\left(x_{n}, x_{0}\right)$ is also bounded. This together with (3.5) implies that the limit of $\left\{\phi\left(x_{n}, x_{0}\right)\right\}$ exists. Put

$$
\lim _{n \rightarrow \infty} \phi\left(x_{n}, x_{0}\right)=d
$$

From Lemma 1.4, we have, for any positive integer $m$, that

$$
\begin{aligned}
\phi\left(x_{n+m}, x_{n+1}\right) & =\phi\left(x_{n+m}, \Pi_{C_{n}} x_{0}\right) \leq \phi\left(x_{n+m}, x_{0}\right)-\phi\left(\Pi_{C_{n}} x_{0}, x_{0}\right) \\
& =\phi\left(x_{n+m}, x_{0}\right)-\phi\left(x_{n+1}, x_{0}\right),
\end{aligned}
$$

for all $n \geq 0$. This together with (3.7) implies that

$$
\lim _{n \rightarrow \infty} \phi\left(x_{n+m}, x_{n+1}\right)=0
$$

uniformly for all $m$, holds. By using Lemma 1.2, we get that

$$
\lim _{n \rightarrow \infty}\left\|x_{n+m}-x_{n+1}\right\|=0
$$


uniformly for all $m$, holds. Then $\left\{x_{n}\right\}$ is a Cauchy sequence, therefore there exists a point $p \in C$ such that $x_{n} \rightarrow p$.

Since $x_{n+1}=\Pi_{C_{n}} x_{0} \in C_{n}$, from the definition of $C_{n}$, we have

$$
\phi\left(x_{n+1}, y_{n}\right) \leq\left(1-\alpha_{n}\right) \phi\left(x_{n+1}, x_{n}\right)+\alpha_{n} \phi\left(x_{n+1}, x_{0}\right)
$$

This together with (3.9) and $\lim _{n \rightarrow \infty} \alpha_{n}=0$ implies that

$$
\lim _{n \rightarrow \infty} \phi\left(x_{n+1}, y_{n}\right)=0
$$

Therefore, by using Lemma 1.2, we obtain

$$
\lim _{n \rightarrow \infty}\left\|x_{n+1}-y_{n}\right\|=0
$$

Since $j$ is uniformly norm-to-norm continuous on bounded sets, then we have

$$
\lim _{n \rightarrow \infty}\left\|J x_{n+1}-J y_{n}\right\|=\lim _{n \rightarrow \infty}\left\|J x_{n+1}-J x_{n}\right\|=0 .
$$

Noticing that

$$
\begin{aligned}
\left\|J x_{n+1}-J y_{n}\right\| & =\left\|J x_{n+1}-\left(\alpha_{n} J x_{0}+\beta_{n} J x_{n}+\gamma_{n} J z_{n}\right)\right\| \\
& =\left\|\alpha_{n}\left(J x_{n+1}-J x_{0}\right)+\beta_{n}\left(J x_{n+1}-J x_{n}\right)+\gamma_{n}\left(J x_{n+1}-J z_{n}\right)\right\| \\
& \geq \gamma_{n}\left\|J x_{n+1}-J z_{n}\right\|-\alpha_{n}\left\|J x_{n+1}-J x_{0}\right\|-\beta_{n}\left\|J x_{n+1}-J x_{n}\right\|,
\end{aligned}
$$

which leads to

$$
\left\|J x_{n+1}-J z_{n}\right\| \leq \frac{1}{\gamma_{n}}\left(\left\|J x_{n+1}-J y_{n}\right\|+\alpha_{n}\left\|J x_{0}-J x_{n+1}\right\|+\beta_{n}\left\|J x_{n+1}-J x_{n}\right\|\right) .
$$

From (3.14) and $\lim _{n \rightarrow \infty} \alpha_{n}=0,0<\gamma \leq \gamma_{n} \leq 1$, we obtain

$$
\lim _{n \rightarrow \infty}\left\|J x_{n+1}-J z_{n}\right\|=0
$$

Since $J^{-1}$ is also uniformly norm-to-norm continuous on bounded sets, then we obtain

$$
\lim _{n \rightarrow \infty}\left\|x_{n+1}-z_{n}\right\|=0
$$

Observe that

$$
\left\|x_{n}-z_{n}\right\| \leq\left\|x_{n+1}-x_{n}\right\|+\left\|x_{n+1}-z_{n}\right\| .
$$


It follows from (3.10) and (3.18) that

$$
\begin{aligned}
& \left\|z_{n}-x_{n}\right\| \longrightarrow 0, \text { as } n \longrightarrow \infty, \\
& d\left(x_{n}, T x_{n}\right) \longrightarrow 0, \quad \text { as } n \longrightarrow \infty
\end{aligned}
$$

Since we have proved that $x_{n} \rightarrow p$, which together with (3.21) and that, $T$ is weak relatively multivalued nonexpansive mapping, implies that $p \in F(T)$.

Finally, we prove that $p=\Pi_{F(T)} x_{0}$. From Lemma 1.4, we have

$$
\phi\left(p, \Pi_{F(T)} x_{0}\right)+\phi\left(\Pi_{F(T)} x_{0}, x_{0}\right) \leq \phi\left(p, x_{0}\right)
$$

On the other hand, since $x_{n+1}=\Pi_{C_{n}} x_{0}$ and $F(T) \subset C_{n}$, for all $n$. Also from Lemma 1.4, we have

$$
\phi\left(\Pi_{F(T)} x_{0}, x_{n+1}\right)+\phi\left(x_{n+1}, x_{0}\right) \leq \phi\left(\Pi_{F(T)} x_{0}, x_{0}\right) .
$$

By the definition of $\phi(x, y)$, we know that

$$
\lim _{n \rightarrow \infty} \phi\left(x_{n+1}, x_{0}\right)=\phi\left(p, x_{0}\right)
$$

Combining (3.22), (3.23), and (3.24), we know that $\phi\left(p, x_{0}\right)=\phi\left(\Pi_{F(T)} x_{0}, x_{0}\right)$. Therefore, it follows from the uniqueness of $\Pi_{F(T)} x_{0}$ that $p=\Pi_{F(T)} x_{0}$. This completes the proof.

When $\alpha_{n} \equiv 0$ in Theorem 3.1, we obtain the following result.

Theorem 3.2. Let $E$ be a uniformly convex and uniformly smooth Banach space, let $C$ be a nonempty closed convex subset of $E$, and let $T: C \rightarrow C$ be a weak relatively multivalued nonexpansive mapping such that $F(T) \neq \emptyset$. Assume that $\left\{\alpha_{n}\right\}_{n=0}^{\infty}$ is a sequences in $[0,1]$ such that $0 \leq \alpha_{n} \leq \alpha<1$ for some constant $\alpha \in(0,1)$. Define a sequence $\left\{x_{n}\right\}$ in $C$ by the following algorithm:

$$
\begin{gathered}
x_{0} \in C \quad \text { arbitrarily, } \\
y_{n}=J^{-1}\left(\alpha_{n} J x_{n}+\left(1-\alpha_{n}\right) J z_{n}\right), \quad z_{n} \in T x_{n} \\
C_{n}=\left\{z \in C_{n-1}: \phi\left(z, y_{n}\right) \leq \phi\left(z, x_{n}\right)\right\}, \quad n \geq 1, \\
C_{0}=C, \\
x_{n+1}=\prod_{C_{n}} x_{0},
\end{gathered}
$$

then $\left\{x_{n}\right\}$ converges to $q=\prod_{F(T)} x_{0}$.

\section{Applications for Maximal Monotone Operators}

In this section, we apply the above results to prove some strong convergence theorem concerning maximal monotone operators in a Banach space $E$. 
Let $A$ be a multivalued operator from $E$ to $E^{*}$ with domain $D(A)=\{z \in E: A z \neq \emptyset\}$ and range $R(A)=\{z \in E: z \in D(A)\}$. An operator $A$ is said to be monotone if

$$
\left\langle x_{1}-x_{2}, y_{1}-y_{2}\right\rangle \geq 0
$$

for each $x_{1}, x_{2} \in D(A)$ and $y_{1} \in A x_{1}, y_{2} \in A x_{2}$. A monotone operator $A$ is said to be maximal if its graph $G(A)=\{(x, y): y \in A x\}$ is not properly contained in the graph of any other monotone operator. We know that if $A$ is a maximal monotone operator, then $A^{-1} 0$ is closed and convex. The following result is also well known.

Theorem 4.1 (see Rockafellar [10]). Let $E$ be a reflexive, strictly convex and smooth Banach space and let $A$ be a monotone operator from $E$ to $E^{*}$. Then $A$ is maximal if and only if $R(J+r A)=E^{*}$ for all $r>0$.

Let $E$ be a reflexive, strictly convex and smooth Banach space, and let $A$ be a maximal monotone operator from $E$ to $E^{*}$. Using Theorem 4.1 and strict convexity of $E$, we obtain that for every $r>0$ and $x \in E$, there exists a unique $x_{r}$ such that

$$
J x \in J x_{r}+r A x_{r}
$$

Then we can define a single valued mapping $J_{r}: E \rightarrow D(A)$ by $J_{r}=(J+r A)^{-1} J$ and such a $J_{r}$ is called the resolvent of $A$. We know that $A^{-1} 0=F\left(J_{r}\right)$ for all $r>0$, see $[9,11]$ for more details. Using Theorem 3.1, we can consider the problem of strong convergence concerning maximal monotone operators in a Banach space. Such a problem has been also studied in $[1,7,10-20]$.

Theorem 4.2. Let $E$ be a uniformly convex and uniformly smooth Banach space, let $A$ be a maximal monotone operator from $E$ to $E^{*}$ with $A^{-1} 0 \neq \emptyset$, and let $J_{M}: E \rightarrow 2^{E}$ be a multivalued mapping defined as follows:

$$
J_{M}: x \longmapsto\left\{y \in E: y=J_{r} x, r \in M\right\}, \quad x \in E,
$$

where $M$ is a set of real numbers such that $\inf M>0 . J_{M}$ is called the multivalued resolvent of $A$. Then $J_{M}$ is a weak relatively nonexpansive multivalued mapping.

Proof. Since

$$
\begin{aligned}
F\left(J_{M}\right) & =\left\{p \in E: J_{r} p=p, r \in M\right\} \\
& =\left\{p \in E: p \in A^{-1} 0, r \in M\right\} \\
& =A^{-1} 0,
\end{aligned}
$$

so that $F\left(J_{M}\right) \neq \emptyset$. Next, we show

$$
\phi(p, z) \leq \phi(p, x), \quad \forall p \in F\left(J_{M}\right), \forall x \in E, \forall z \in J_{M} x
$$


From the monotonicity of $A$, we have

$$
\begin{aligned}
\phi(p, z)= & \|p\|^{2}-2\langle p, J z\rangle+\|z\|^{2} \\
= & \|p\|^{2}+2\langle p, J x-J z-J x\rangle+\left\|J_{r} w\right\|^{2} \\
= & \|p\|^{2}+2\langle p, J x-J z\rangle-2\langle p, J x\rangle+\|z\|^{2} \\
= & \|p\|^{2}-2\langle z-p-z, J x-J z-J x\rangle-2\langle p, J x\rangle+\|z\|^{2} \\
= & \|p\|^{2}-2\langle z-p, J x-J z-J x\rangle \\
& +2\langle z, J x-J z\rangle-2\langle p, J x\rangle+\|z\|^{2} \\
\leq & \|p\|^{2}+2\langle z, J x-J z\rangle-2\langle p, J x\rangle+\|z\|^{2} \\
= & \|p\|^{2}-2\langle p, J x\rangle+\|x\|^{2}-\|z\|^{2}+2\langle z, J x\rangle-\|w\|^{2} \\
= & \phi(p, x)-\phi(z, x) \\
\leq & \phi(p, x) .
\end{aligned}
$$

Finally, we show $\widetilde{F}\left(J_{M}\right)=F\left(J_{M}\right)$. Observe that $\widetilde{F}\left(J_{M}\right) \supseteq F\left(J_{M}\right)$ is obvious. Next, we show $\tilde{F}\left(J_{M}\right) \subseteq F\left(J_{M}\right)$. Let $\left\{z_{n}\right\} \subset E$ be a sequence such that $z_{n} \rightarrow p$ and $\lim _{n \rightarrow \infty} d\left(z_{n}, J_{M} z_{n}\right)=0$. There exist sequences $\left\{y_{n}\right\}$ in $E$ and $\left\{r_{n}\right\} \subseteq M$ such that

$$
\lim _{n \rightarrow \infty}\left\|z_{n}-y_{n}\right\|=0, \quad y_{n}=J_{r_{n}} z_{n}
$$

Since $J$ is uniformly norm-to-norm continuous on bounded sets, we obtain

$$
\frac{1}{r_{n}}\left(J z_{n}-J y_{n}\right) \longrightarrow 0
$$

It follows from

$$
\frac{1}{r_{n}}\left(J z_{n}-J y_{n}\right) \in A J_{r_{n}} z_{n}
$$

and the monotonicity of $A$ that

$$
\left\langle w-J_{r_{n}} z_{n}, w^{*}-\frac{1}{r_{n}}\left(J z_{n}-J J_{r_{n}} z_{n}\right)\right\rangle \geq 0
$$

for all $w \in D(A)$ and $w^{*} \in A w$. Letting $n \rightarrow \infty$, we have $\left\langle w-p, w^{*}\right\rangle \geq 0$ for all $w \in D(A)$ and $w^{*} \in A w$. Therefore, from the maximality of $A$, we obtain $p \in A^{-1} 0=F\left(J_{M}\right)$. Hence $J_{M}$ is a weak relatively nonexpansive multivalued mapping. This completes the proof.

By using Theorems 3.1 and 4.2, we directly obtain the following result. 
Theorem 4.3. Let E be a uniformly convex and uniformly smooth Banach space, let $A$ be a maximal monotone operator from $E$ to $E^{*}$ with $A^{-1} 0 \neq \emptyset$, let $J_{M}$ be a multivalued resolvent of $A$, where inf $M>$ 0 , and let $\left\{\alpha_{n}\right\},\left\{\beta_{n}\right\},\left\{\gamma_{n}\right\}$ be three sequences of real numbers such that $\alpha_{n} \rightarrow 0$ and $0<\gamma \leq \gamma_{n} \leq 1$ for some constant $\gamma \in(0,1)$. Define a sequence $\left\{x_{n}\right\}$ of $C$ as follows:

$$
\begin{gathered}
x_{0} \in C \quad \text { arbitrarily, } \\
y_{n}=J^{-1}\left(\alpha_{n} J x_{0}+\beta_{n} J x_{n}+\gamma_{n} J z_{n}\right), \quad z_{n} \in J_{M} x_{n} \\
C_{n}=\left\{z \in C_{n-1}: \phi\left(z, y_{n}\right) \leq\left(1-\alpha_{n}\right) \phi\left(z, x_{n}\right)+\alpha_{n} \phi\left(z, x_{0}\right)\right\}, \quad n \geq 1, \\
C_{0}=C, \\
x_{n+1}=\prod_{C_{n}} x_{0},
\end{gathered}
$$

where $J$ is the duality mapping on $E$. Then $\left\{x_{n}\right\}$ converges strongly to $\Pi_{A^{-1} 0} x_{0}$, where $\Pi_{A^{-1} 0}$ is the generalized projection from $E$ onto $A^{-1} 0$.

\section{Acknowledgment}

This project is supported by the National Natural Science Foundation of China under Grant (11071279).

\section{References}

[1] J. S. Jung, "Strong convergence theorems for multivalued nonexpansive nonself-mappings in Banach spaces," Nonlinear Analysis. Series A, vol. 66, no. 11, pp. 2345-2354, 2007.

[2] N. Shahzad and H. Zegeye, "On Mann and Ishikawa iteration schemes for multi-valued maps in Banach spaces," Nonlinear Analysis. Series A, vol. 71, no. 3-4, pp. 838-844, 2009.

[3] Y. Song and H. Wang, "Convergence of iterative algorithms for multivalued mappings in Banach spaces," Nonlinear Analysis. Series A, vol. 70, no. 4, pp. 1547-1556, 2009.

[4] S. Homaeipour and A. Razani, "Weak and strong convergence theorems for relatively nonexpansive multi-valued mappings in Banach spaces," Fixed Point Theory and Applications, vol. 2011, article 73, 2011.

[5] Y. I. Alber, "Metric and generalized projection operators in Banach spaces: properties and applications," in Theory and Applications of Nonlinear Operators of Accretive and Monotone Type, vol. 178 of Lecture Notes in Pure and Applied Mathematics, pp. 15-50, Marcel Dekker, New York, NY, USA, 1996.

[6] Y. I. Alber and S. Reich, "An iterative method for solving a class of nonlinear operator equations in Banach spaces," Panamerican Mathematical Journal, vol. 4, no. 2, pp. 39-54, 1994.

[7] S. Kamimura and W. Takahashi, "Strong convergence of a proximal-type algorithm in a Banach space," SIAM Journal on Optimization, vol. 13, no. 3, pp. 938-945, 2002.

[8] I. Cioranescu, Geometry of Banach Spaces, Duality Mappings and Nonlinear Problems, vol. 62 of Mathematics and its Applications, Kluwer Academic Publishers, Dordrecht, The Netherlands, 1990.

[9] W. Takahashi, Nonlinear Functional Analysis, Yokohama Publishers, Yokohama, Japan, 2000.

[10] R. T. Rockafellar, "On the maximality of sums of nonlinear monotone operators," Transactions of the American Mathematical Society, vol. 149, pp. 75-88, 1970.

[11] W. Takahashi, Convex Analysis and Approximation Fixed Points, Yokohama Publishers, Yokohama, Japan, 2000.

[12] D. Butnariu, S. Reich, and A. J. Zaslavski, "Asymptotic behavior of relatively nonexpansive operators in Banach spaces," Journal of Applied Analysis, vol. 7, no. 2, pp. 151-174, 2001. 
[13] D. Butnariu, S. Reich, and A. J. Zaslavski, "Weak convergence of orbits of nonlinear operators in reflexive Banach spaces," Numerical Functional Analysis and Optimization, vol. 24, no. 5-6, pp. 489-508, 2003.

[14] Y. Censor and S. Reich, "Iterations of paracontractions and firmly nonexpansive operators with applications to feasibility and optimization," Optimization, vol. 37, no. 4, pp. 323-339, 1996.

[15] F. Kohsaka and W. Takahashi, "Strong convergence of an iterative sequence for maximal monotone operators in a Banach space," Abstract and Applied Analysis, vol. 2004, no. 3, pp. 239-249, 2004.

[16] S. Ohsawa and W. Takahashi, "Strong convergence theorems for resolvents of maximal monotone operators in Banach spaces," Archiv der Mathematik, vol. 81, no. 4, pp. 439-445, 2003.

[17] S. Reich, "Constructive techniques for accretive and monotone operators," in Applied Nonlinear Analysis, pp. 335-345, Academic Press, New York, NY, USA, 1979, in Proceedings of the 3rd International Conference University of Texas, Arlington, Tex, USA, 1978.

[18] S. Reich, "A weak convergence theorem for the alternating method with Bregman distances," in Theory and Applications of Nonlinear Operators of Accretive and Monotone Type, A. G. Kartsatos, Ed., vol. 178 of Lecture Notes in Pure and Applied Mathematics, pp. 313-318, Marcel Dekker, New York, NY, USA, 1996.

[19] M. V. Solodov and B. F. Svaiter, "Forcing strong convergence of proximal point iterations in a Hilbert space," Mathematical Programming, vol. 87, no. 1, Ser. A, pp. 189-202, 2000.

[20] Y. Su and X. Qin, "Monotone CQ iteration processes for nonexpansive semigroups and maximal monotone operators," Nonlinear Analysis. Series A, vol. 68, no. 12, pp. 3657-3664, 2008. 


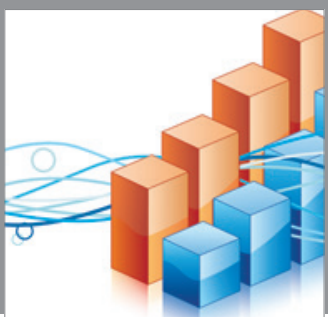

Advances in

Operations Research

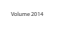

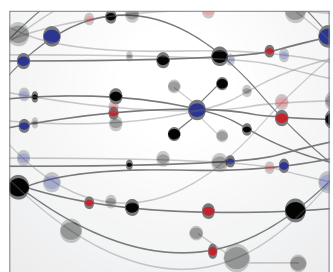

\section{The Scientific} World Journal
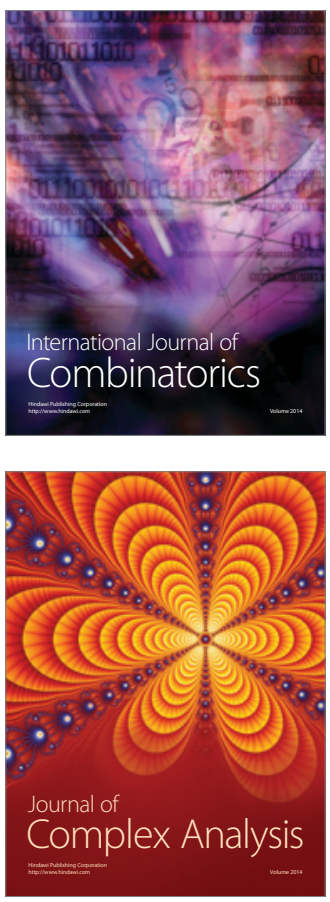

International Journal of

Mathematics and

Mathematical

Sciences
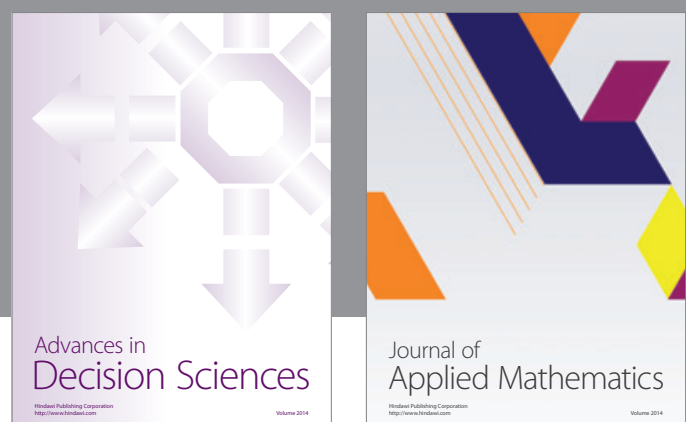

Journal of

Applied Mathematics
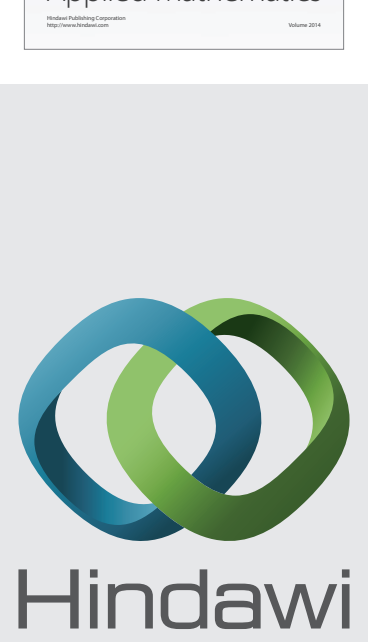

Submit your manuscripts at http://www.hindawi.com
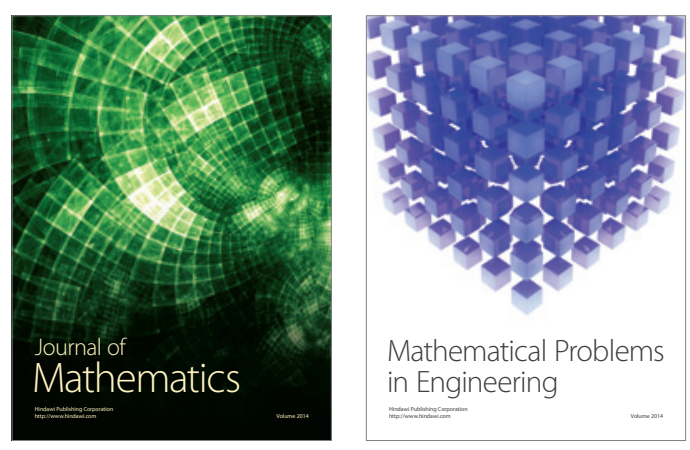

Mathematical Problems in Engineering
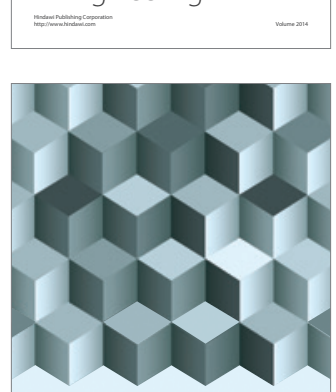

Journal of

Function Spaces
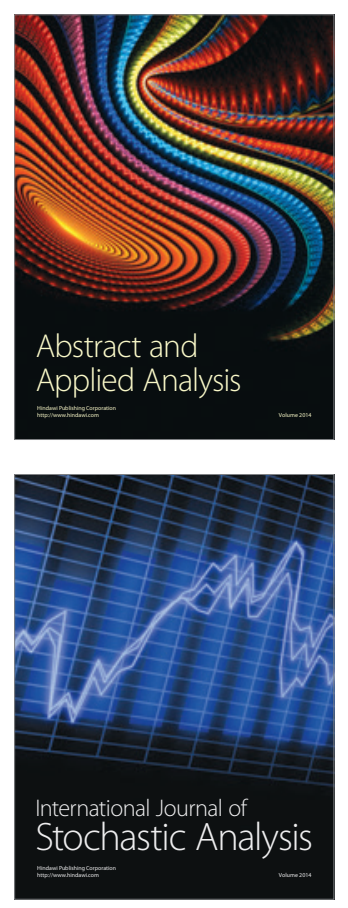

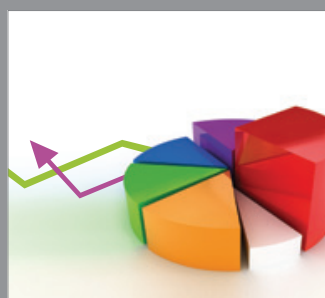

ournal of

Probability and Statistics

Promensencen
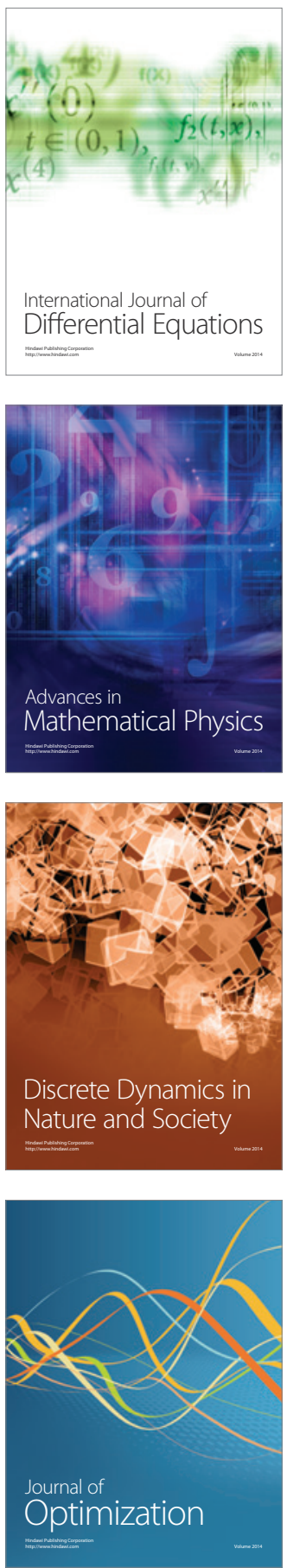